\title{
Probabilistic Seismic Damage Assessment of RC Buildings Based on Nonlinear Dynamic Analysis
}

\author{
Yeudy F. Vargas ${ }^{1, *}$, Lluis G. Pujades ${ }^{1}$, Alex H. Barbat ${ }^{1}$ and Jorge E. Hurtado ${ }^{2}$ \\ ${ }^{1}$ Universidad Politécnica de Cataluña Department of Geotechnical Engineering and Geosciences, Jordi Girona 1-3, \\ Building D2, Campus Norte UPC, 08034 Barcelona, Spain \\ ${ }^{2}$ Universidad Nacional de Colombia Universidad Nacional de Colombia, Apartado 127, Manizales, Colombia
}

\begin{abstract}
The incremental dynamic analysis is a powerful tool for evaluating the seismic vulnerability and risk of buildings. It allows calculating the global damage of structures for different PGAs and representing this result by means of damage curves. Such curves are used by many methods to obtain seismic risk scenarios at urban level. Even if the use of this method in a probabilistic environment requires a relevant computational effort, it should be the reference method for seismic risk evaluation. In this article we propose to assess the seismic expected damage by using nonlinear dynamic analysis. We will obtain damage curves by means of the incremental dynamic analysis combined with the damage index of Park \& Ang. The uncertainties related to the mechanical properties of the materials and the seismic action will be considered. The probabilistic damage curves obtained can be used to calculate not only seismic risk scenarios at urban level, but also to estimate economic losses.
\end{abstract}

Keywords: Damage curves, incremental dynamic analysis, uncertainties.

\section{INTRODUCTION}

For evaluating the seismic risk of existing structures, the damage grade has to be established for a given earthquake. There are several methodologies for calculating this damage grade; one of them is the Vulnerability Index Method [1-6] in which the action is defined by means of the European Macroseismic Scale, EMS-98 [7], by using macroseismic intensities and describing the seismic structural behaviour by means of a vulnerability index. Another widely invoked methodology is based on the capacity spectrum method developed by Freeman et al. [8] and Freeman [9] and further developed by Fajfar and Gaspersic [10], Chopra and Goel [11] and by Fajfar [12], among others. Although this approach is useful for large scale assessments, it can provide results which are not in agreement with those obtained by means of the incremental nonlinear dynamic analysis. The later allows calculating the global damage of structures for different PGAs and representing this result by means of damage curves. Such curves are used by many methods for obtaining seismic risk scenarios at urban level. In this article we use the algorithm proposed by Vamvatsikos and Cornell [13] to obtain probabilistic damage curves by considering as random variables the mechanical properties of the materials and the seismic action [14-17].

\section{DESCRIPTION OF THE STUDIED BUILDING}

The reinforced concrete framed building analyzed in this study, with 4 levels and 3 spans, has been designed and used

*Address correspondence to this author at the Universidad Politécnica de Cataluña, Department of Geotechnical Engineering and Geosciences, Jordi Girona 1-3, Building D2, Campus Norte UPC, 08034 Barcelona, Spain; Tel: +34934016496; E-mail: yeudy.felipe.vargas@upc.edu in this article as a testbed for the proposed seismic vulnerability evaluation method; concrete framed building is shown in Fig. (1a) which also shows its geometrical dimensions. Due to its symmetry, the building can be modeled as bidimensional using a single frame (Fig. 1b). The characteristics of the beams and columns of this frame are given in Table $\mathbf{1}$.

The material of the beams and columns of the structural model follows an elastoplastic hysteretic rule with a postyielding hardening of $5 \%$. Yielding surfaces are defined by the bending moment-axial load interaction diagram for columns and bending moment-curvature for beams. The applied dead and live loads follow the recommendations given by the Eurocode 2 [18] for reinforced concrete structures. The mechanical properties of concrete and steel are the values commonly used in the design of such buildings and the values are shown in Table 2. Design standards require characteristic strength values for the materials obtained during the quality control process, from compression and tension tests in concrete and steel samples, respectively. By means of these tests, the concrete compressive strength, $f c$, and the elastic modulus of the steel, Es, can be modelled as random variables, a fact which is very useful due to the probabilistic approach applied in this article. Table 2 shows the mean, $\mu$, the standard deviation, $\sigma$, and the coefficient of variation $\mathrm{cov}$ of these random variables and we assume that they follow a normal distribution. Other possible uncertainties, like those related to cracking and crushing of concrete, strain hardening and ultimate strength of steel, other effects such as the considering the slab in the model, axial force variations on column strength, just to name a few, can be also included in the probabilistic structural analysis, but in this article we consider only the uncertainties in the variables of Table 2 . In the following, we use the building described herein in order to explain the developments proposed in the article. 
a)

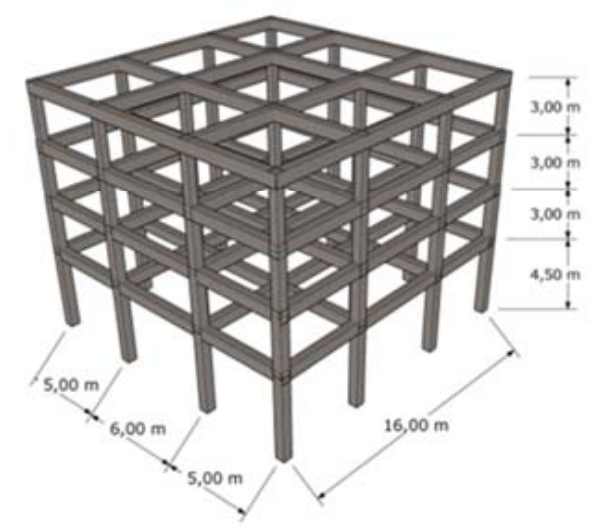

b)

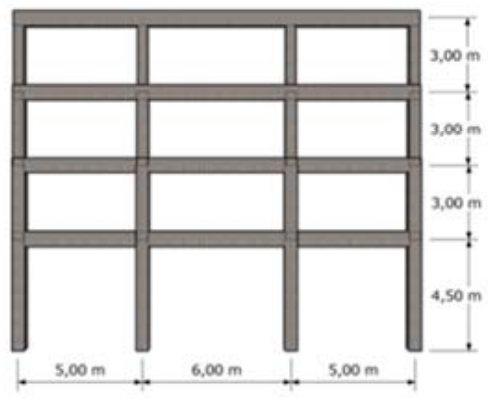

Fig. (1). a) One of the buildings studied in this article and b) 2D model.

Table 1. Characteristics of the elements of one of the studied buildings (Fig. 1). $b, h$ and $\rho$ denote base, height and steel quantity of the cross sections of the structural elements, respectively.

\begin{tabular}{|c|c|c|c|c|c|c|}
\hline Storey & \multicolumn{3}{|c|}{ Columns } & \multicolumn{3}{|c|}{ Beams } \\
\hline 2 & 0.5 & 0.5 & 0.02 & 0.45 & 0.6 & 0.0066 \\
\hline 3 & 0.45 & 0.45 & 0.015 & 0.45 & 0.6 & 0.0066 \\
\hline
\end{tabular}

Table 2. Characteristics of the input random variables. $\mu, \sigma$ and $c o v$ represent the mean, the standard deviation and the coefficient of variation of the input random variables.

\begin{tabular}{|c|c|c|c|}
\hline & $\boldsymbol{\mu}$ & $\boldsymbol{\sigma}$ & $\operatorname{cov}$ \\
\hline \hline$f_{c}(\mathrm{kN})$ & $2.1 \mathrm{E} 04$ & $2.1 \mathrm{E} 03$ & 0.1 \\
\hline$E s(\mathrm{kPa})$ & $2 \mathrm{E} 08$ & $2 \mathrm{E} 07$ & 0.1 \\
\hline
\end{tabular}

\section{INCREMENTAL DYNAMIC ANALYSIS}

A nonlinear dynamic analysis, NLDA, performed for a given accelerogram provides the time history response of a building and, then, the maximum response variables of the structure like the displacement at the roof, the global damage index according to a certain criterion, etc. can be calculated. Scaling the accelerogram with a given increment of the PGA, for values starting from a lower limit (which includes the elastic range) until reaching an upper one, corresponding to the building collapse and performing for each increment a NLDA, we can obtain a curve relating the PGAs to the maximum roof displacement, usually called dynamic pushover curve. When a curve relates the PGAs to the global damage index, it is denoted as damage curve. When, instead of a single accelerogram, several of them are used to perform nonlinear dynamic analyses and statistics are made with the obtained results, we are faced with an incremental dynamic analysis, IDA [13]. Summarizing, IDA allows obtaining the nonlinear dynamic response of a structure, for a group of earthquakes which are scaled to different measures of intensity which, in this article, is the Peak Ground Acceleration (PGA). Besides, this procedure has been extended to include uncertainties in the structural properties [19]. An important source of the uncertainty in the seismic response is the random variability of the ground-motion prediction whose influence has been studied by Bommer \& Crowley [20]. The forecasting of the ground-motion parameters has been studied by Abrahamson et al. [21, 22], Bommer et al. [23] and Arroyo and Ordaz [24]. According to the probabilistic simulation approach used in this article, it is also necessary to describe the seismic action as a random variable. To do that, 10 earthquakes have been selected from the European database [25] and they can be seen in Fig. (2). This figure also 
Table 3. Characteristics of the selected earthquakes.

\begin{tabular}{|c|c|c|c|c|c|c|c|}
\hline Station Name & Date & \multicolumn{2}{|c|}{ Epicentre (Degrees) } & Depth (km) & $\begin{array}{l}\text { Magnitude } \\
\text { (Ms) }\end{array}$ & Local Geology & $\begin{array}{c}\text { Epicentral } \\
\text { Distance (km) }\end{array}$ \\
\hline San Rocco & 15.09 .1976 & 46.29 & 13.20 & 15 & 6.06 & Stiff soil & 17 \\
\hline San Rocco & 15.09 .1976 & 46.32 & 13.16 & 12 & 5.98 & Stiff soil & 17 \\
\hline Kotor Nas Rakit & 24.05 .1979 & 42.23 & 18.76 & 5 & 6.34 & Rock & 21 \\
\hline Ponte Corvo & 07.05.1984 & 41.73 & 13.90 & 8 & 5.79 & Rock & 31 \\
\hline Matelica & 26.09 .1997 & 43.03 & 12.86 & 6 & 5.9 & Rock & 20 \\
\hline Tricarico & 05.05 .1990 & 40.65 & 15.92 & 12 & 5.6 & Rock & 20 \\
\hline Izmit-M-Istasyonu & 13.09 .1999 & 40.70 & 30.02 & 13 & 5.9 & Stiff soil & 13 \\
\hline
\end{tabular}

$\mu_{\text {Depth }}=11 \mathrm{~km}, \sigma_{\text {Depth }}=3.8 \mathrm{~km}, \mu_{\mathrm{ED}}=22.9 \mathrm{~km}, \sigma_{\mathrm{ED}},=7.65 \mathrm{~km}, \mu_{\mathrm{Ms}}=6.13, \sigma_{\mathrm{Ms}}=0.55$

shows the spectra of the selected earthquakes, their average spectrum, and the spectrum type 1 for a soil type A of Eurocode 8 (EC8) [26]. Fig. (2) shows that the procedure which has been used for selecting accelerograms compatibles with a seismic zone represented by a spectral shape allows obtaining a good fit. The list of these earthquakes and of their main characteristics is given in Table $\mathbf{3}$.

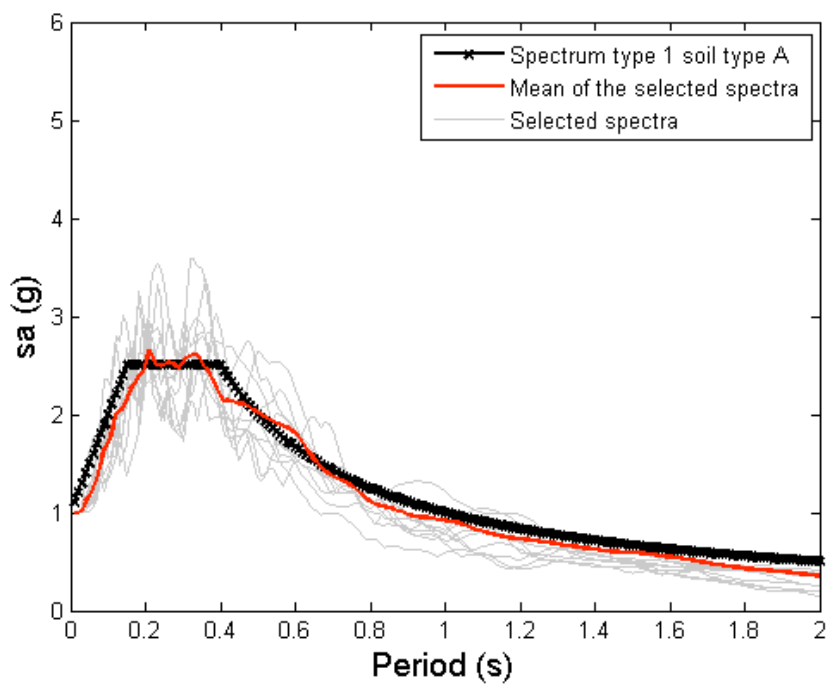

Fig. (2). Spectra calculated from the procedure based on the mean spectrum.

Several methods to establish the optimal number of accelerograms required to perform the inelastic dynamic analyses have been studied by Hancock et al. [27] and they conclude that the exact number depends on the damage measures which are considered and also on the predictability of the mentioned damage measures. Most of these methods are based on the magnitude and the spectral shape. Notwithstanding, we are not interested herein in obtaining an optimal number of accelerograms but a measure of the uncertainties in the structural response of the structures subjected to seis- mic actions. For this reason, in this article, the selection of the accelerograms is based on the difference between the mean of a group of response spectra and the target spectrum; the accelerograms corresponding to these spectra have been previously normalized to $1 \mathrm{~g}$. This difference is calculated based on the absolute cumulative difference between the target spectrum and the mean spectrum in several points; these points are separated by equal period intervals of $0.01 \mathrm{~s}$. The spectral shape selected in this study to the seismic action in the area corresponds to the type 1 of the EC8 which has a surface-wave magnitude greater than 5.5.

In order to include the uncertainties related to the structural characteristics, we use the Monte Carlo method. It is well known that the spatial variability between the characteristics of the structural elements greatly influences on the results $[28,29]$. Therefore, we decided to consider it by generating, for all the columns of the same story of the building, one random sample for the compressive strength of concrete, $f_{c}$, and, for each column of the same story, one random sample of the elastic modulus of the steel, Es. We used the same criterion to generate random samples for the characteristics of the materials of the beams of this story. It is important to note that the samples corresponding to each story are independent. This consideration is based on the fact that usually the structural elements of the same storey are made of the same concrete but the properties of the reinforcement can be supposed as independent from rebar to rebar. On the other hand, it is worth to recall that the objective of this article is the seismic risk assessment of an individual building; nevertheless, this objective could be extended to classes of structures existing in urban areas, taking into account, when modeling their risk, the building to building variation of the structural characteristics within a structural class. Further discussion of this issue can be found in Crowley et al. [30]. Afterwards, we generated random samples of the mechanical properties of the materials and performed nonlinear dynamic analyses, NLDA, for different accelerograms linearly scaled to values of the PGAs ranging from $0.1 \mathrm{~g}$ to $1.4 \mathrm{~g}$ at intervals 
of $0.1 \mathrm{~g}$. We used the Latin Hypercube method [31] for generating random samples of the material properties and for combining these randomly with the accelerograms. Therefore, we performed 1000 NLDA for each PGA. The seismic global damage index of the building, which is necessary to calculate the damage curve, is obtained as a weighted mean of the damage indices initially defined at structural element level.

Several damage indices have been proposed for the elements of reinforced concrete structures starting from a postprocess of the nonlinear dynamic response. Some of them are described in the following. A first simple method calculates the damage index as the ratio of the maximum ductility achieved during the seismic action to the ultimate ductility at element level and this is addressed herein as the ductility based damage index [32, 33].

$\mathrm{DI}_{E}=\frac{\mu_{m}}{\mu_{u}}$

where $\mu_{m}$ and $\mu_{n}$ are the maximum and ultimate ductilities, respectively, and the subscript $\mathrm{E}$ stays for element level damage index. Banon \& Veneziano [34] proposed a damage index using a nonlinear equation considering the maximum and yielding ductility, the dissipated hysteretic energy, the yielding action and a numerator corresponding to monotonic loading.

$\mathrm{DI}_{E}=\sqrt{\frac{\left(\frac{\mu_{m}}{\mu_{y}}-1\right)^{2}+\left(1.1\left(\frac{2 E_{h}}{F_{y} \mu_{y}}\right)^{0.38}\right)^{2}}{\text { Numerator for monotonic load }}}$

where $\mu_{y}$ is the yielding ductility, $E_{h}$ is the hysteretic energy dissipated and $F_{y}$ is the yielding action. The damage index of Park \& Ang [35] is the sum of the maximum ductility divided by the ultimate ductility, that is, the ductility based damage index, with a term related to the dissipated energy. The corresponding equation is:

$\mathrm{DI}_{E}=\frac{\mu_{m}}{\mu_{u}}+\frac{\beta E_{h}}{F_{y} \mu_{u} \delta_{y}}$

where $\beta$ is a non-negative parameter which represent the effect of cyclic loading on structural damage and $\delta_{y}$ is the yield displacement. Roufaiel and Meyer [36] proposed a damage index considering the maximum, the yielding and the ultimate ductility and, besides, the maximum and yield actions:

$$
\mathrm{DI}_{E}=\frac{\frac{\mu_{m}}{F_{m}}-\frac{\mu_{y}}{F_{y}}}{\frac{\mu_{u}}{F_{u}}-\frac{\mu_{y}}{F_{y}}}
$$

where $F_{m}$ and $F_{u}$ are the maximum and the ultimate actions, respectively. Bracci et al. [37] proposed a damage index as the ratio of the work done at the maximum ductility to the work done at the ultimate ductility

$\mathrm{DI}_{E}=\frac{E_{m}}{E_{u}}$ where $E_{m}$ and $E_{u}$ are the work done at the maximum ductility and the work done at the ultimate ductility, respectively. Cosenza et al. [38] proposed a damage index as the ratio of the maximum ductility minus one to the ultimate ductility minus one

$$
\mathrm{DI}_{E}=\frac{\mu_{m}-1}{\mu_{u}-1}
$$

In all the cases, the global damage index of the structure, $D I$, is a weighted mean of the element damages, in which the weights are the ratio of the hysteretic energy dissipated by each element to the total hysteretic energy dissipated by the structure [39]:

$\mathrm{DI}=\sum_{i} \lambda_{i} \mathrm{DI}_{E}$

where $D I$ is the dynamic analysis based global damage index of the structure, $\lambda_{i}$ is the ratio of the dissipated hysteretic energy of an element $E$ to the dissipated hysteretic energy of the entire structure. Fig. (3) shows the evolution with PGA of all these global damage indices of the building of Fig. (1), considering the uncertainties related to the mechanical properties of the materials and of the seismic action.

In Fig. (3), one can see the important differences among the calculated damage indices, not only in mean but also in scattering, when uncertainties are considered. In this article, based on the results obtained in Fig. (3), we decided to select a damage index considering both the effect of ductility based damage and the damage due to dissipated energy. Two of the considered damage indices comply with this condition: those of Banon and Veneziano Park and Ang [34, 35]. The values obtained for the global damage indices are similar but we believe that the Park \& Ang index is more adequately to represent the probabilistic damage curves because it clearly allows identifying which is the contribution of the dissipated hysteretic energy to the global damage index. According to the original calibration of the damage index made by Park \& Ang [39] a value of 0.4 indicates that the cost of repairing the structure exceeds the cost of completely replace it, while a damage index of 1 indicates collapse. For this reason, in this article, when the damage index of Park \& Ang is higher than 1 , its value is set to 1 . This makes sense, because, for higher PGAs, the standard deviation of the damage index decreases, what indicates that for higher PGAs the collapse uncertainty reduces. In Fig. (4) we show the mean and the standard deviation of the damage curves based on the damage index of Park \& Ang. Such curves are the base of many procedures to estimate the seismic expected damage in urban areas.

\section{CONCLUSION}

In this work the risk of a framed reinforced concrete building has been assessed taking into account that the input variables are random. Not only the compressive strength of the concrete and the elastic modulus of the steel have been treated as random variables, but also the seismic action has been considered in a stochastic way. The approach to evaluate the expected damage of the building is based on the incremental dynamic analysis. 

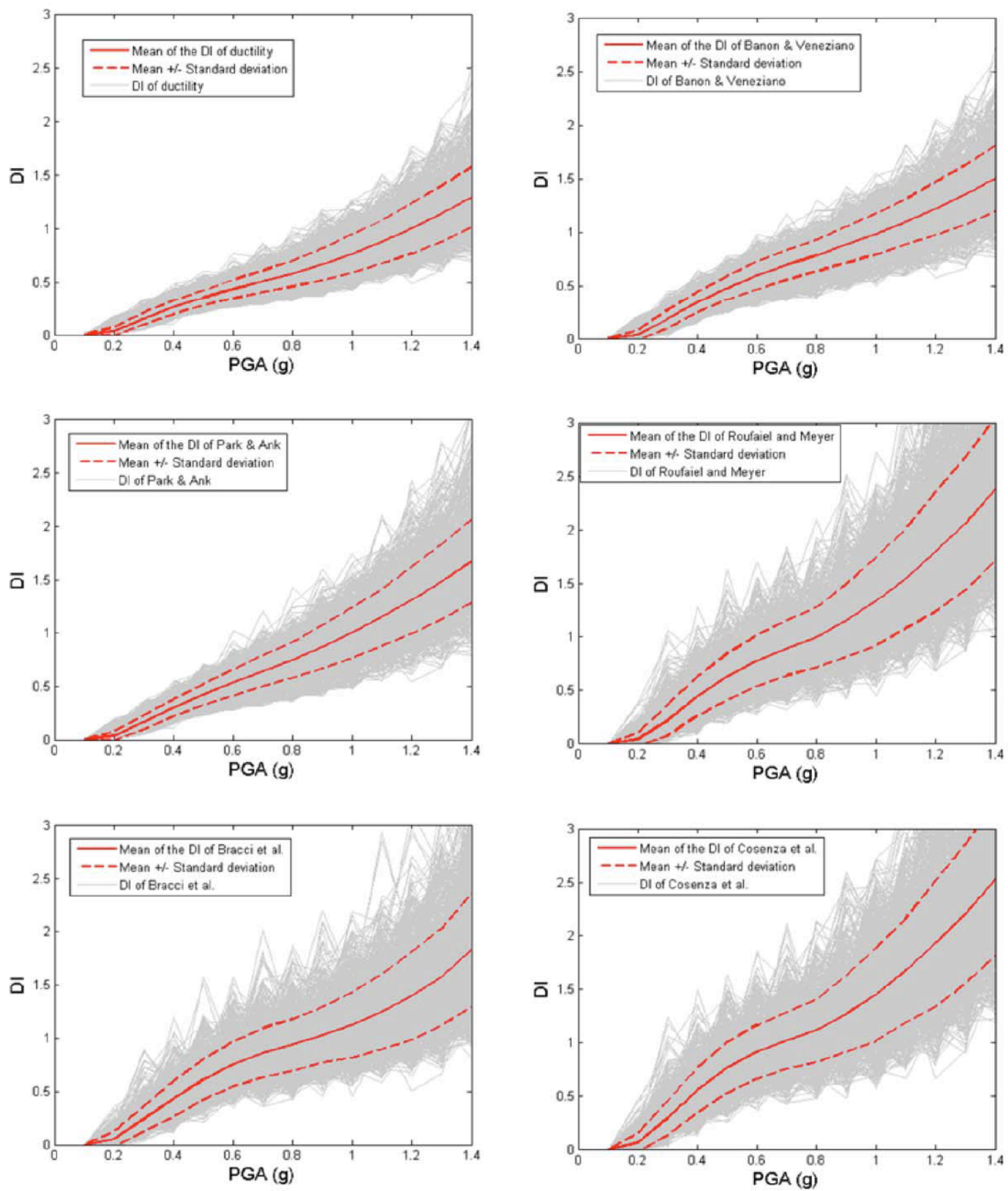

Fig. (3). Graphics of the discussed global damage indices represented in function of the PGA, calculated by means of non-linear dynamic analyses for the building of Fig. (1).

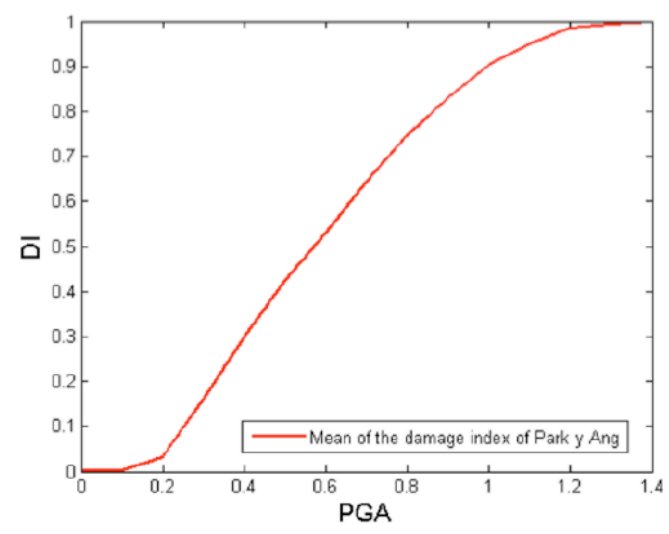

a)

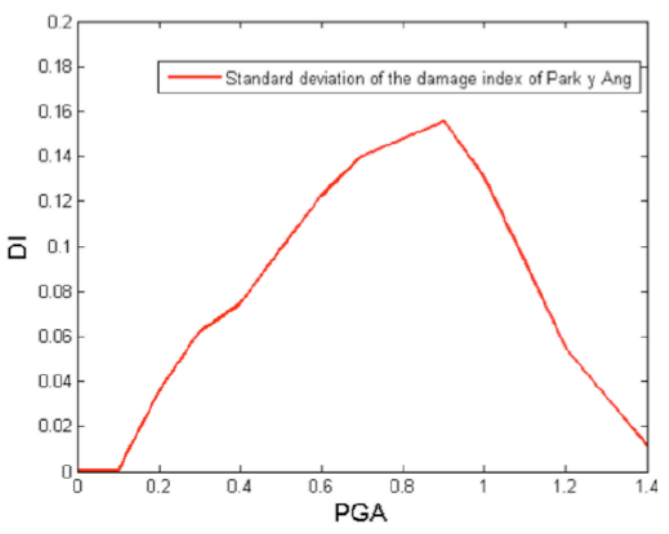

b)

Fig. (4). a) Mean and b) standard deviation of the damage index of Park \& Ang. 
An important conclusion is that, despite working with advanced non-linear structural analysis methods, the results show significant uncertainties when taking into account the randomness of the input variables. For this reason, the parameters influencing upon the seismic damage curves of the structures must be considered as random. Simplified deterministic procedures based on characteristic values usually leads to conservative results but some abridged assumptions on the definition of the seismic actions and on the estimation of the seismic damage states and thresholds can lead also to underestimate the real damage that can occur in a structure.

One of the major applications of the results obtained in this article is that one can estimates probabilistic seismic risk scenarios, based on non-linear dynamic analyses, because the required probabilistic damage curves defined in a parametric way, by means of their mean and their standard deviation, are available now.

\section{CONFLICT OF INTEREST}

The authors confirm that this article content has no conflict of interest.

\section{ACKNOWLEDGEMENTS}

This work has been partially funded by the Spanish Government, by the European Commission and with FEDER funds, through the research projects: CGL2008-00869/BTE, CGL2011-23621, SEDUREC-CONSOLIDERCSD200600060, INTERREG:POCTEFA 2007-2013/73/08, MOVEFT7-ENV-2007-1-211590 and DESURBS-FP7-2011-261652. Y.F. Vargas-Alzate, has been the holder of a scholarship and a contract funded by the Geological Institute of Catalonia and the Polytechnic University of Catalonia by means of a bilateral agreement.

\section{REFERENCES}

[1] A. H. Barbat, U. Mena, and F. Yépez, "Evaluación probabilista del riesgo sísmico en zonas urbanas", Revista internacional de métodos numéricos para cálculo y diseño en ingeniería vol. 14, no. 2, pp. 247-268, 1998.

[2] A. H. Barbat, L. G. Pujades, N. Lantada, and R. Moreno, "Performance of buildings under earthquakes in Barcelona, Spain", Computer-Aided Civil and Infrastructure Engineering, vol. 21, pp. 573-593, 2006.

[3] N. Lantada, L. G. Pujades, and A. H. Barbat, "Vulnerability index and capacity spectrum based methods for urban seismic risk evaluation. A comparison", Natural Hazards, vol. 51, pp. 501-524, 2009.

[4] A. H. Barbat, M. L. Carreño, L. G. Pujades, N. Lantada, O. D. Cardona, and M. C. Marulanda, "Seismic vulnerability and risk evaluation methods for urban areas. A review with application to a pilot area", Structure and Infrastructure Engineering, vol. 6, no. 12, pp. 17-38, 2010.

[5] A. H. Barbat, M. L. Carreño, O. D. Cardona, and M. C. Marulanda, "Evaluación holística del riesgo sísmico en zonas urbanas", Revista internacional de métodos numéricos para cálculo y diseño en ingeniería, vol. 27, no. 1, pp. 3-27, 2011.

[6] S. Lagomarsino, and S. Giovinazzi, "Macroseismic and mechanical models for the vulnerability and damage assessment of current buildings", Bulletin of Earthquake Engineering vol. 4, no. 4, pp. 415-443, 2006.

[7] G. Grünthal, European Macroseismic Scale 1998, EMS-98. Cahiers du centre Européen de Géodynamique et de Séismologie. Conseil de L'Europe, 1998; 15.

[8] S. A. Freeman, J. P. Nicoletti, and J. V. Tyrell, "Evaluations of existing buildings for seismic risk - a case study of Puget Sound
Naval Shipyard, Bremerton, Washington," In: Proceedings of $1^{\text {st }}$ U.S. National Conference of Earthquake Engineering, EERI, Berkeley, 1975, pp. 113-122.

[9] S. A. Freeman, "Development and use of capacity spectrum method," In: Proceedings $6^{\text {th }}$ U.S. National Conference of Earthquake Engineering, EERI, Seattle 1998; CD-ROM.

[10] P. Fajfar, and P. Gaspersic, "The N2 method for the seismic damage analysis of RC buildings", Earthquake Engineering and Structural Dynamics, vol. 25, no. 1, pp. 31-46, 1996.

[11] A. K. Chopra, and R. K. Goel, "Capacity-Demand-Diagram Methods for Estimating Seismic Deformation of Inelastic Structures: SDOF Systems,”. PEER Report 1999/02 Berkeley: Pacific Earthquake Engineering Research Center, University of California; 1999.

[12] P. Fajfar, "Capacity spectrum based on inelastic demand spectra", Earthquake Engineering and Structural Dynamics, vol. 28, no. 9, pp. 979-993, 1999.

[13] D. Vamvatsikos, and C. A. Cornell, "The incremental dynamic analysis", Earthquake Engineering and Structural Dynamics vol. 31, no. 3, pp. 491-514, 2002.

[14] Y. F. Vargas, L. G. Pujades, A. H. Barbat, and J. E. Hurtado, "Capacity, fragility and damage in reinforced concrete buildings: a probabilistic approach", Bulletin of earthquake engineering, vol. 11, pp. 2007-2032, 2013.

[15] Y. F. Vargas, L. G. Pujades, A. H. Barbat, and J. E. Hurtado, "Evaluación probabilista de la capacidad, fragilidad y daño sísmico en edificios de hormigón armado", Métodos numéricos para cálculo y diseño en ingeniería, vol. 29, no. 2, pp. 63-78, 2013.

[16] Y. F. Vargas, L. G. Pujades, A. H. Barbat, and J. E. Hurtado, "Probabilistic seismic risk evaluation of RC buildings", Proceedings of the ICE-Structures and Buildings, vol. 167, no. 6, pp. 327-336, 2013.

[17] R. Gonzalez-Drigo, J. A. Avila-Haro, A. H. Barbat, L. G. Pujades, Y. F. Vargas, S. Lagomarsino, and S. Cattari, "Modernist URM buildings of Barcelona, "Seismic vulnerability and risk assessment", International Journal for Architectural Heritage,vol. 9, no. 3, pp. 214-230, 2015.

[18] CEN, Eurocode 2, "Design of Concrete Structures - Part 1. General-Common Rules for Building and Civil Engineering Structures, European committee for standardization, 2004.

[19] D. Vamvatsikos, and M. Fragiadakis "Incremental dynamic analysis for estimating seismic performance sensitivity and uncertainty", Earthquake Engineering and Structural Dynamics, vol. 39, no. 2, pp. 141-163, 2010.

[20] J. Bommer, and H. Crowley, "The influence of ground motion variability in earthquake loss modeling", Bulletin of Earthquake Engineering vol. 4, no. 3, pp. 231-248, 2006.

[21] N. A. Abrahamson, P. G. Somerville, and C. A. Cornell, "Uncertainty in numerical ground motion predictions," In: Proceedings of $4^{\text {th }}$ U.S. National Conference of Earthquake Engineering, EERI, 1991, pp. 407-416, 1991.

[22] J. J. Egozcue, A. H. Barbat, J. A. Canas, J. Miquel, and E. Banda, "A method to estimate occurrence probabilities in low seismic activity regions", Earthquake Engineering and Structural Dynamics, vol. 20, no. 1, pp. 43-60, 1991.

[23] J. Bommer, P. J. Stafford, J. E. Alarcón, and S. Akkar, "The influence of magnitude range on empirical ground-motion prediction", Bulletin of Seismological Society of America vol. 97, pp. 2152-2170, 2007.

[24] D. Arroyo, and M. Ordaz, "On the forecasting of ground-motion parameters for probabilistic seismic hazard analysis", Earthquake Spectra vol. 27, no. 1, pp. 1-21, 2011.

[25] N. Ambraseys, P. Smit, R. Sigbjornsson, P. Suhadolc, and B. Margaris, Internet-Site for European Strong-Motion Data, European Commission, Research-Directorate General, Environment and Climate Programme. http://www.isesd.hi.is/ESD_Local/frameset. htm [12 april 2014]

[26] CEN. Eurocode 8, Design of Structures for Earthquake Resistance. Part 1: General Rules, Seismic Actions and Rules for Building, European committee for standardization; 2004.

[27] J. Hancock, J. J. Bommer, and P. J. Sttaford, "Numbers of scaled and matched accelerograms required for inelastic dynamic analyses", Earthquake Engineering and Structural Dynamics vol. 37, no. 14, pp. 1585-1607, 2008.

[28] P. Franchin, P. E. Pinto, and P. Rajeev, "Confidence factor?", Journal of Earthquake Engineering, vol. 14, no. 7, pp. 989-1007, 2010. 
[29] J. E. Hurtado, and A. H. Barbat, "Improved stochastic linearization method using mixed distributions", Structural Safety, vol. 18, no. 1, pp. 49-62, 1996.

[30] H. Crowley, J. J. Bommer, R. Pinho, and J. F. Bird, "The impact of epistemic uncertainty on an earthquake loss model", Earthquake Engineering and Structural Dynamics vol. 34, no. 14, pp. 1635$1685,2005$.

[31] M. Kalos, and P. A. Whitlock, Monte Carlo Methods, John Wiley and Sons, 1986.

[32] S. Oller, and A. H. Barbat, "Moment-curvature damage model for bridges subjected to seismic loads", Computer Methods in Applied Mechanics and Engineering, vol. 195, pp. 4490-4511, 2006.

[33] J. Faleiro, S. Oller, and A. H. Barbat, "Plastic-damage seismic model for reinforced concrete frames", Computers and Structures, vol. 86, no. 7-8, pp. 581-597, 2008.

[34] H. Banon, and D. Veneziano, "Seismic safety of reinforced concrete members and structures", Earthquake Engineering and Structural Dynamics, vol. 10, no. 2, pp. 179-193, 1982.
[35] Y-J. Park, and A. H-S. Ang, "Mechanistic seismic damage model for reinforced concrete", Journal of Structural Engineering ASCE, vol. 111, no. 4, pp. 722-739, 1985

[36] M. S. L. Roufaiel, and C. Meyer, "Analytical model of hysteretic behaviour of RC frames", Journal of Structural Engineering ASCE, vol. 113, no. 3, pp. 429-457, 1987.

[37] J. M. Bracci, A. M. Reinhorn, J. B. Mander, and S. K. Kunnath, "Deterministic for Seismic Damage Evaluation of Reinforced Concrete Structures", NCEER-89-0033, National Center for Earthquake Engineering Research, State University of New York at Buffalo1989.

[38] E. Cosenza, G. Manfredi, and R. Ramasco, "The use of damage functionals in earthquake engineering: A comparison between different methods", Earthquake Engineering and Structural Dynamics, vol. 22, no. 10, pp. 855-868, 1993.

[39] Y-J. Park, A. H-S. Ang, and Y. Kwei-Wen, "Seismic damage analysis of reinforced concrete buildings", Journal of Structural Engineering ASCE, vol. 111, no. 4, pp. 740-757, 1985.

Received: November 04, 2014

Revised: November 24, 2014

Accepted: December 05, 2014

(c) Vargas et al.; Licensee Bentham Open.

This is an open access article licensed under the terms of the Creative Commons Attribution Non-Commercial License (http://creativecommons.org/licenses/ by-nc/3.0/) which permits unrestricted, non-commercial use, distribution and reproduction in any medium, provided the work is properly cited. 